\title{
Overview of Internet of Things and Its Application in Tobacco Industry Enterprise Management
}

\author{
Huali Zheng*1 \\ ${ }^{1}$ Production Management Department, China tobacco Zhejiang Industrial Co., Ltd Hangzhou, China
}

\begin{abstract}
With the continuous efforts of human beings, great progress has been made in the development of society, and socioeconomic level and science and technology have achieved great development. The concept of the Internet of Things (IoT) was first proposed in the 1990s. So far, research on the IoT has been ongoing. The development of the IoT to this day has achieved certain results and is gradually applied in various industries. The tobacco industry has always occupied a large proportion in China's economic market and is an indispensable part of my country's national economy. Reasonable and effective business management can promote the stable development of China's tobacco industry. This article first introduces the IoT technology, then analyzes the advantages of the IoT application in tobacco industry enterprise management, and finally discusses the practical application of the IoT in tobacco industry enterprise management.
\end{abstract}

\section{Introduction}

Since 2001, the Chinese government has accelerated the pace of tobacco industry system reform, stepped up efforts to cultivate star brands, and accelerated industry concentration. In recent years, the Chinese central government has focused on the construction of the tobacco industry network and applied new technologies to the tobacco industry, and has achieved a series of achievements. However, compared with international multinational tobacco companies, the gap is still very large. After continuous development of the IoT, its technology has become more and more mature and mature. More and more enterprises are beginning to introduce the IoT technology into the management of the company, which is of great help to improve the information management level of the enterprise. It helps enterprises to achieve the healthy and stable development. Tobacco enterprises are an important part of my country's economic enterprises. The management of enterprises should be continuously studied to improve the management level of enterprises. Therefore, in order to improve the market competitiveness of enterprises, it is necessary to improve the management level of enterprises. With the help of advanced management technology, enterprises improve their management level and enhance their competitiveness [1].

\section{2 loT technology analysis}

In the 1990s, the emergence of the IoT as a new thing has aroused great interest. There are many experts and scholars devoted to the research of the IoT. After years of continuous research, the field of IoT has achieved certain results. In essence, the IoT is the information interaction between things, including the interaction between people and things. The IoT is a distributed collaborative network. The connection between information sensing devices and the information interaction between them are realized through the Internet. Therefore, information collection, information transmission and information application are the basic components of the IoT. Therefore, through the above analysis, we can see that the IoT contains three basic characteristics, namely: comprehensive perception, intelligent processing and reliable transmission. The following will describe these aspects in detail [2].

\subsection{Comprehensive information perception.}

Collect and acquire information of objects through radio frequency identification (RFID), sensors and twodimensional codes. Typical sensor networks such as traditional environmental monitoring, radio frequency identification, video monitoring, road monitoring and indication, infrared sensing, and even safe production, crop growth, and pest and disease monitoring have become the basic information gathering part of the IoT network. The special information collection system of the physical world such as the global positioning system and the global monitoring system also provides a wide range of information acquisition capabilities for the IoT. The types of information cover the comprehensive needs of work, health, human life, and social activities, and are given location and identity characteristics of the information for later information processing and information tracing and efficient application [3]. 


\subsection{Reliable information transmission capability.}

Information exchange and information sharing of objects connected to the information network through the communication network, and is not restricted by time and place. Because the huge information provided by the sensor network needs to reach wherever it is needed, "seamless arrival" has become a new trend in the development of information networks. Due to the great differences between application environments, if you want to achieve the goal of "seamless reach", you need to rely on multiple technologies, which is difficult to achieve with a single technology. Therefore, the integration of multiple transmission technologies to provide transmission services to any user has become the basic form of network multi-mode development. At the same time, the types of information will become more abundant, and transmission quality assurance will become more diverse [4].

\subsection{Intelligent information capabilities. \\ processing}

When processing massive amounts of perceptual data, because traditional data processing methods are difficult to achieve the expected goals, it is necessary to use intelligent computing technology and make decisionmaking and control based on the analysis results. Information services, no matter in point-to-point, point-tomultipoint, or information search modes, are difficult to fulfill the massive information processing service requirements in the era of the IoT. Therefore, the development of a new intelligent information processing service model has become a key foundation for building a reliable IoT society.

In order to better understand how the IoT plays a role in enterprise management, from the perspective of information flow, this article gives a functional model of the IoT, as shown in Figure 1.

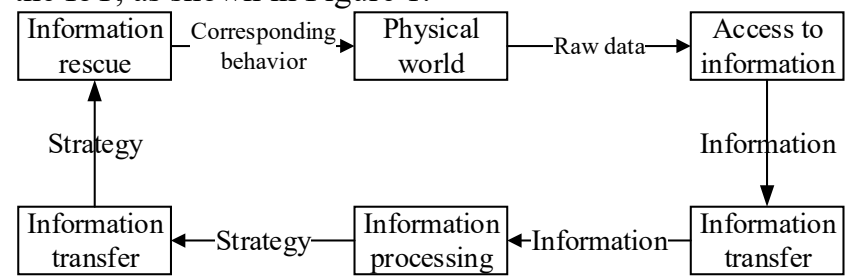

Fig 1. IoT function model

It is widely believed in the industry that the IoT framework includes three layers, namely: perception layer, transmission layer and application layer, as shown in Figure 2. The perception layer is located at the bottom of the IoT architecture. Its main function is to realize information perception and intelligent control of the surrounding environment. It is necessary to establish a set of sensor network to collect information on the surrounding environment, generally using ZigBee technology, sensor technology, RFID technology, etc. The information to be collected includes: temperature and humidity, various gas concentrations, air pressure, light intensity, and video information. According to this information, remote control can be achieved by connecting the control module to the relay node [5].

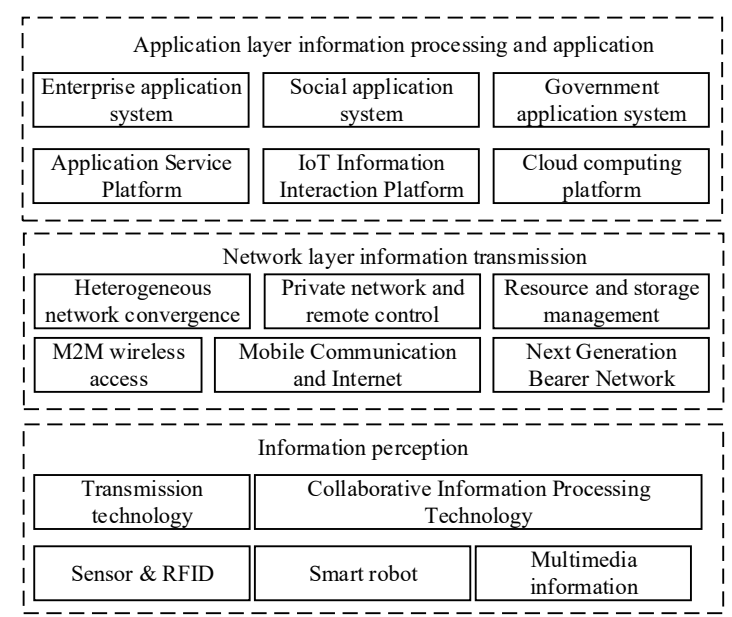

Fig 2. IoT system architecture

\section{Tobacco loT three-tier architecture design and its advantages in management}

\subsection{Tobacco loT three-tier architecture design}

The tobacco IoT system consists of software and hardware The terminal perception layer is mainly composed of RFID equipment, GPS, infrared sensors, laser scanners, etc. It is mainly used to collect and interact with cigarette information generated during logistics. Strictly control the sorting, storage and distribution of cigarettes. The network transmission layer is mainly composed of Internet and wireless network, supplemented by GPRS and sensor network. The application layer mainly contains data information analysis modules and intelligent systems for controlling decisions, such as business application systems, sorting management, warehousing management, distribution management, and security monitoring systems Its three-tier architecture is shown in Figure 3. The application of the IoT in this paper in tobacco industry enterprises is based on these three-layer structure [6].

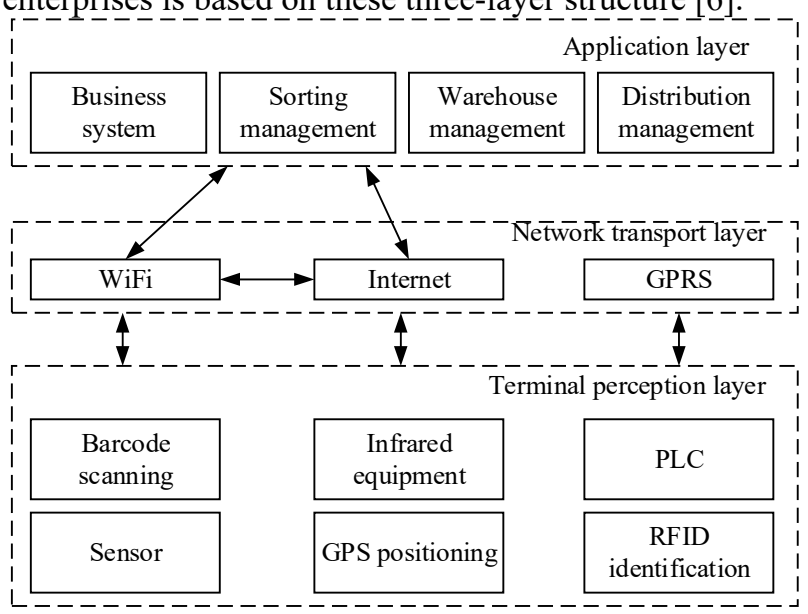

Fig 3. The three-layer architecture of the Tobacco IoT 


\subsection{The management advantages of the loT in tobacco industry enterprises}

\subsubsection{Conducive to tracking management of tobacco products.}

The IoT technology has been applied in many areas of tobacco industry. It is based on Internet technology, combined with global positioning system, communication network, geographic information system and sensor technology. The IoT can effectively realize automatic storage, real-time monitoring and intelligent control of tobacco products. It is beneficial to the positioning, tracking and management of a series of processes of tobacco products from production to consumption [7].

\subsubsection{The loT can improve the level of enterprise management.}

The IoT technology can monitor and manage the production and transportation processes of tobacco industry enterprises in real time through sensor technology, and can upload data and share information through the Internet in real time. Enterprise managers use data analysis tools to analyze the collected data. Combined with the actual operation of the enterprise and the results of data analysis, enterprise managers adjust production and transportation, which plays an important role in improving the production efficiency and logistics management level of the enterprise.

\subsubsection{The IoT technology can enable tobacco industry enterprises to contact tobacco leaf producers to promote the systematic operation of enterprises.}

Through the technology of the IoT, the tobacco-related materials within the tobacco industry enterprises are matched with the tobacco leaf producers, and the two can communicate with each other to control the quality of the tobacco leaves in real time, which can meet the needs of the enterprises for the production of tobacco leaves in a timely manner [8].

\section{Research on the application of IoT in tobacco industry enterprise management}

The introduction of the IoT into the management of tobacco industry enterprises is of great significance. It can improve the management level of enterprises, save the management costs of enterprises. Using the IoT to achieve the connection between the production of actual objects and the Internet can enhance the production efficiency of the enterprise's tobacco, make the overall production capacity of the enterprise regulated in time, thus avoiding a lot of unnecessary cost waste and further increasing the economic benefits of the enterprise. The following is a detailed analysis of the application of the IoT in the management of tobacco industry enterprises [9].

\subsection{Application of IoT in warehouse management}

The intelligent warehousing subsystem includes three functional modules: entering the warehouse, warehousing management and leaving the warehouse management. System enter the warehouse management module to automatically allocate the cargo position according to the number and brand of cigarettes, obtain the barcode information of the cigarette through the barcode scanner and write it into the RFID tag on the tray. The forklift puts the pallet into the corresponding position, and then the RFID reader-writer associates the RFID information of the pallet with the label information of the cargo location to realize storage management. The warehousing management module reads the tag information in the warehouse through the RFID reader to obtain the current cigarette information in the warehouse. The forklift driver updates the location tag information through the RFID reader, and after the pallet is transported to the destination location, the new location information is modified. Many sensors and cameras, such as temperature, humidity, infrared, and smoke, are installed in the cigarette warehouse. These terminal sensing devices monitor the various conditions in the warehouse in real time. The sensor equipment sends the real-time monitoring information back to the warehouse management platform in time to realize warehouse management. The outbound management module is sent to the forklift terminal according to the outbound instruction, and the forklift driver finds the corresponding cargo location and pallet according to the instruction to take out the goods, and at the same time uses the RFID reader to change the label information of the cargo location.

Through the implementation of the IoT technology, the optimization and upgrading of the warehouse management system can be accelerated. Through the IoT technology, the functions of online information collection, storage cigarette identification, storage cigarette monitoring, back-end server maintenance and local database maintenance are realized, and intelligent storage management of cigarettes is realized. The business system architecture flowchart is shown in Figure 4.

Cigarette products are easily affected by the environment. A good cigarette warehouse must ensure that the temperature and humidity are within a certain range, so as to ensure the storage quality of cigarettes. If the temperature and humidity are abnormal, the cigarette may be moldy and spoiled. Real-time temperature and humidity data in the warehouse is obtained by adopting wireless sensing and detection technology in the IoT. Then transfer the collected data to the computer through the recorder, run the monitoring software to view the real-time temperature and humidity data of the recording monitoring point, and set the temperature and humidity alarms on the computer. In this way, the temperature and humidity changes of the entire warehouse can be viewed in real time through the network, and timely response can be made according to the situation to improve the storage management level of the distribution center [10]. 


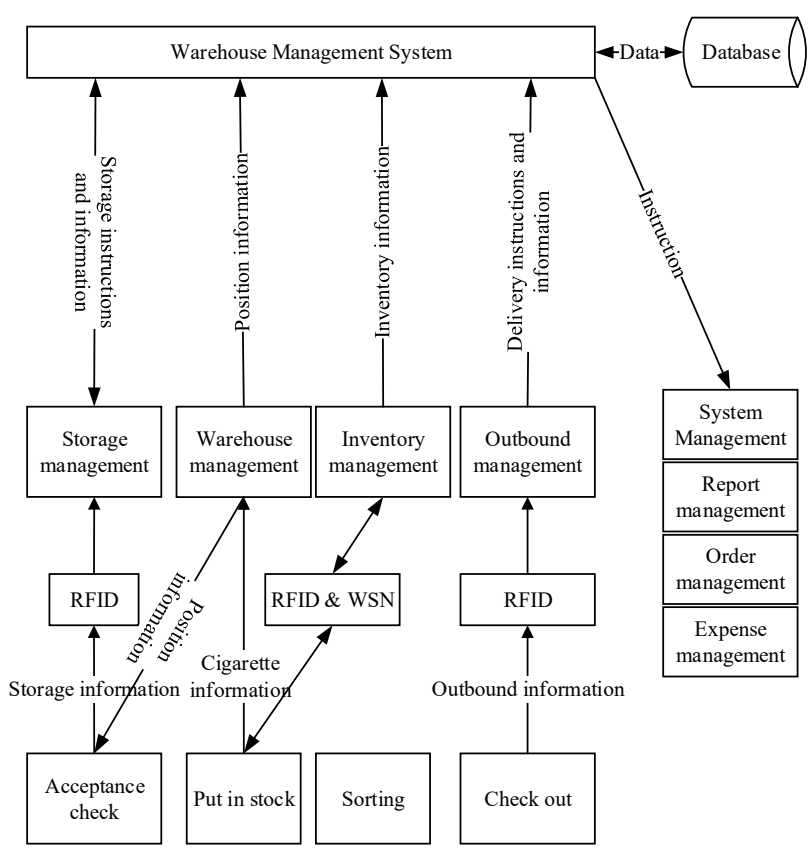

Fig 4. Warehousing business system architecture flowchart

\section{2 loT monitoring and management of the production environment}

Cigarette production requires high temperature and humidity in the workshop, and changes in temperature and humidity will directly affect the production quality of cigarettes. Install multiple temperature and humidity sensors connected to the monitoring center system in the warehouse to build a "sensor monitoring network" for the storage center. At the same time, RFID tags are added to related equipment, facilities and resources to realize the storage and perception of the basic attribute information and status information of each logistics resource, and the monitoring information is integrated with the results of the perception monitoring to realize the all-round refinement of the trinity of environment, location and time. Improve the safety and control of cigarette logistics and storage management. The temperature and humidity data are collected at a certain time interval through the sensor and displayed in real-time graphics in the monitoring and command center. When the temperature or humidity of the warehouse exceeds the set range, the system will issue an alarm and automatically start the temperature and humidity adjustment equipment for processing.

After receiving the temperature and humidity data, the temperature and humidity tag can periodically send data to the remote reader, and these data are transmitted to the monitoring screen of the central control room in real time. When any detected value exceeds the working threshold, an eye-catching indicator will be used to give an alarm prompt in the corresponding position of the monitoring screen. So that once any ring node has an alarm situation, it can immediately sense on the monitoring platform, determine the location, understand and trace the actual situation through the video and audio monitoring records, and improve on-site management capabilities.

\subsection{Management of the plant area by the loT}

Tobacco industrial enterprises have a large production area and a lot of personnel and vehicles. It is difficult for traditional management methods to implement refined management of the enterprise. The use of IoT technology to build a monitoring and warning system for the entire plant area can effectively realize the visual and refined management of the enterprise plant area. The system includes perimeter alarm system, video monitoring system, exit control system, intrusion alarm system, patrol management system, parking lot management system. Through this system, the main areas in the plant are monitored and managed to form a comprehensive regional protection system for detection, monitoring and management in the area. By integrating the abovementioned subsystems, the linkage control necessary for the comprehensive protection and management formed by the above-mentioned subsystems in accordance with the principles of management and police organization within the region, between regions and even in the overall scope is realized. At the same time, the system is networked with the building equipment management system to achieve linkage control with the fire alarm system, building equipment automation control and management system in the corresponding areas, between areas, and even within the entire scope of the building.

\section{Conclusion}

In summary, IoT is applied to the management of tobacco industry enterprises, the use of IoT can accelerate the increase of tobacco product output. Simplify the steps in tobacco production, and the connection between the Internet and equipment can avoid a lot of repeated cost waste and product backlog. The application of the IoT technology in the economic benefits of tobacco companies can rely on the advantages of the Internet itself to save product procurement costs and maximize its own economic benefits. Secondly, it can expand the extra economy and create more value for the enterprise. The IoT technology can also integrate the various systems of the enterprise, integrate the small system with the overall system, and provide technical support for the enterprise to strengthen management and improve the system. In the future, we will continue to deeply study the internal structure of the IoT technology and the core guidance of the operation and management of tobacco industry enterprises. In order to propose a more scientific and feasible and efficient management method, we establish a sound tobacco enterprise product management system, and promote the steady development of my country's tobacco industry.

\section{References}

1. S.B. Shen, Q.L. Fan, P. Zong, et al. Research on Architecture and Related Technology of Internet of Things. Journal of Nanjing University of Posts and Telecommunications, 2009, vol.29, no.6, pp.1-11. 
2. R. Rodrigo, A. Cristina, Key management systems for sensor networks in the context of the Internet of Things. Computers and Electrical Engineering, 2011, vol.37, no.2, pp.147-159.

3. M. Hou, Research on Application of Internet of Things Technology in Cigarette Logistics Management. Marketing Management Review, 2018, no.4, 144-144.

4. W. Zhu, R. He, Design and Development of Tobacco Recipe Library Feeding Management System Based on Internet of Things. Technology Innovation and Application, 2020, no.7, pp.86-87+91.

5. W.C. Jiang, The Application of Internet of Things Technology in the Management of Tobacco Enterprises in the New Period. China Market, 2020, no.4, pp.97-98.

6. H. Rolf, Accountability in the Internet of Thing. Computer Law \& Security Review, 2011, vol.27, no.2, pp.133-138.

7. J.C. Zhang, Research on Intelligent Monitoring System of Tobacco Storage Environment Based on Internet of Things Technology. YunNan: Yunnan Normal University, 2019.

8. W.Q. Pei, D.C. Yao, The positive impact of developing tobacco cultivation on regional economic development. Southern Agriculture, 2018, vol.12, no.5, pp.75-79.

9. C.L. Wang, Analysis of the application of big data and data mining technology in the tobacco industry. Technology Style, 2019, no.3, pp.78-78.

10. S. Luo, Talking about the Application of Internet of Things Technology in the Management of Tobacco Enterprises. Knowledge Economy, 2017, no.2, pp.104-105. 